\title{
Genetic Aspects of Growth of Holstein-Friesian Dairy Cows from Birth to Maturity
}

\author{
M. P. Coffey, ${ }^{\star 1}$ J. Hickey, $†$ and S. Brotherstone \\ *Sustainable Livestock Systems, Scottish Agricultural College, Edinburgh EH9 3JG, UK \\ †Institute of Cell, Animal, and Population Biology, University of Edinburgh, Edinburgh, EH9 3JT, UK
}

\begin{abstract}
In general, genetic selection is applied after first calving to traits that manifest themselves during the animal's productive life, mostly during the early part of productive life. This selection policy has had undesirable correlated responses in other economically important traits, such as health and fertility, and may also have had an effect on the growth of animals both during productive life and before first calving. In this study, we analyzed the growth trajectory of dairy heifers that had been selected for maximum production of combined fat and protein (measured in kg; select line) or for average production (control line) in the United Kingdom. Before first calving, these divergent lines were managed as a single group. Select line heifers grew faster than did control line heifers. They were also heavier at first calving, but by the end of 3 lactations, the lines were not significantly different in live weight. Selection primarily for yield and for other traits has led to heifers that grow faster and reach higher growth rates earlier in life. A genetic analysis of birth, weaning, and calving weights yielded heritability estimates of 0.53 (birth weight), 0.45 (weaning weight), and 0.75 (calving weight). Confidence intervals for the genetic correlations between the traits indicated that these BW traits are not under the same genetic control.
\end{abstract}

Key words: growth, dairy heifer, genetic selection

\section{INTRODUCTION}

Growth in beef cattle has been extensively studied in part because of the economic value of growth in this type of farmed livestock. However, growth in dairy cattle has not been studied so extensively, particularly the genetic component of growth. Groen and Vos (1995) estimated the heritability of growth at different stages prior to first calving in Holstein heifers, and Korver et al. (1991) estimated genetic parameters for feed intake

Received November 25, 2004.

Accepted September 19, 2005.

${ }^{1}$ Corresponding author: m.coffey@ed.sac.ac.uk and feed efficiency in growing Holstein heifers. Demeke et al. (2003) estimated heritabilities for BW at various stages of life for a range of European and indigenous breeds and their crosses in Ethiopia.

Some research has focused on growth in lactating dairy cattle because of its economic cost (Spelman and Garrick, 1997), and some has focused on a mechanism for increasing first-lactation yield (Choi et al., 1997). Thus far, no convincing evidence has appeared in the literature to support the economic benefit of genetic selection for higher or lower growth rates or mature size in virgin heifers or lactating dairy cattle. Interest in growth of lactating animals has also extended to predicting BW from linear type classification records (Enevoldsen and Kristensen, 1997; Koenen and Groen, 1998).

Genetic selection in dairy cattle is applied to traits that are measured during the animal's productive life, mostly those recorded during early productive life as genetic evaluations are best calculated from unbiased, early data. Consequently, much genetic research on correlated responses has focused on traits that change after lactation has started. For example, Pryce et al. (1999) showed that selection for yield would result in a decline in fertility and an increase in mastitis and lameness, as the genetic correlation between yield and these traits is unfavorable.

There have been studies on the effect of differing growth rates, either prepubertal or precalving, on subsequent performance (Van Amburgh et al., 1998), but these studies have been based on altering the dietary regimen of growing heifers to effect a change in growth rate. These studies have provided target growth rates at specific points of the growth trajectory to maximize first-lactation performance (Mantysaari et al., 2002) based on the negative effects of accelerated growth during critical developmental phases (Stelwagen and Grieve, 1990) and the requirement by most farmers to calve dairy heifers for the first time at a fixed age of 24 mo. In the United States at least, it is becoming more common for dairy farmers to outsource the rearing of growing heifers to specialist growers (Wolf, 2003).

The practice of calving dairy heifers for the first time at $24 \mathrm{mo}$ of age has been adopted as a result of research 
and extension demonstrating the economic benefits (Hoffman and Funk, 1992). Dairy animals are not mature at this age and continue to accrete body protein during their lactating lives. Coffey et al. (2003) showed that selection for production has altered the profile of body lipid loss and gain during the first 3 lactations. Because body lipid is normally accumulated partly as a function of body protein accretion and partly as a function of degree of maturity, which is also related to protein content, it follows that selection for yield in relatively mature life and concomitant alteration of body lipid profiles might have altered early life growth profiles as well.

Changes in live weight from first calving onward are influenced by milk yield and body lipid content, whereas after adjustment for the predicted weight of conceptus and gravid uterus, growth from birth to first calving has few external influences. Any differences between the growth of animals during this period under uniform management must be a function of environment or genotype or both.

Maintenance requirements for dairy cattle depend largely on live weight (Koenen et al., 1999). A possible growth model assumes that measures of live weight at different ages represent the same genetic trait during the animal's life. An alternative approach considers measurements at different ages as separate traits that are genetically correlated (Arango and Van Vleck, 2002). The objectives of this study were 1) to model the growth of dairy cows of average and high genetic merit from birth to first calving and identify any differences in their growth curves, 2) to extend the analysis and model growth from birth to maturity, and 3) to investigate the genetic associations among birth weight (BTW), weaning weight (WW), and calving weight (CW).

\section{MATERIALS AND METHODS}

\section{Data}

Data were extracted for all cows from birth to the end of lactation 3 from the database of Langhill Farm (Edinburgh, UK) records collected from 1990 until 2002. Bulls used to produce select females in this experimental herd were selected for production ( $\mathrm{kg}$ of fat plus protein) using the 4 highest genetic merit bulls with at least $75 \%$ reliability available in the United Kingdom each year. An equal number of bulls were used to produce control line cows of United Kingdom average merit for kilograms of fat plus protein. The approximately equal number of select line and control line animals were reared from birth to first calving as one management group. After first calving, one-half of each genetic group was assigned to a high-concentrate feed group or a low-concentrate feed group as part of a long-term genotype $\times$ environment interaction trial (Veerkamp et al., 1995).

Prior to first calving, animals were weighed at dates that approximated to major management events. These weights were recorded at birth, weaning, first winter, spring turn-out, mid-summer and subsequent housing, then second winter, turn-out, and summer. Young stock might have only some of the BW records taken depending on season of birth. Milking cows were routinely weighed weekly, and at any weighing event, animals were at different ages because of the variation in their birth date.

The policy for first mating at Langhill Farm was to ensure animals calved for the first time close to $24 \mathrm{mo}$ of age and between August and November. Occasionally, cows calved at a time of year that prevented their offspring from adhering to this policy. Although these offspring may have been retained on the farm for commercial milking, they were not used in the long-term trial. Therefore, their BW records were removed from the dataset. This resulted in a dataset of 47,337 records from 625 animals.

Prior to analysis, all live weight records were adjusted for the predicted weight of the conceptus and gravid uterus (including fluid). This adjustment was made by modeling conceptus total weight using an exponential growth curve from day of conception (ARC, 1980), assuming a BTW of $40 \mathrm{~kg}$ at d 281 of gestation and an additional weight of uterus and fluid of $80 \%$ of calf BW. The parameters of this curve were adjusted proportionately according to the $\mathrm{BW}$ of the calf that the cow subsequently delivered. The daily predicted weight of conceptus at the stage of gestation calculated from subsequent calving date was then subtracted from live weight to produce a weight that was considered to be the nonpregnant weight.

\section{Phenotypic Analyses}

We label these analyses "phenotypic," as no attempt was made to partition the animal genetic component from the permanent environmental component. Note, though, that as the cows are grouped by genetic line, differences between lines represent genetic differences.

\section{Model for Analysis}

Random regression models are suitable for analyzing repeated measures on an individual, where the trait is measured along a continuous scale (Kirkpatrick et al., 1990). Random regression models allow environmental effects that are specific to the time of recording to be included, and the shape of the growth curve at the 
individual animal level can be easily accommodated. Variance components for live weight were estimated using the ASREML statistical package (Gilmour et al., 1998). Pedigree information was not included in the analysis; therefore, animal solutions are combined animal genetic and permanent environmental effects. The random regression model fitted in this study was

$$
y_{i t}=F_{i t}+\sum_{m=0}^{f-1} \beta_{m} X_{m}(t)+\sum_{m=0}^{k-1} \gamma_{m} P_{m}(t)+\varepsilon_{i t}
$$

where $y_{i t}$ is live weight measured on animal $i$ at time $t$ and $\mathrm{F}_{\text {it }}$ represents fixed effects of genetic line (2 groups), year of birth, line $\times$ year of birth interaction, feed group ( 2 groups), line $\times$ feed group interaction, time of measurement (year and week of measurement), and age at first calving in months (linear and quadratic) for animal $i$. Note, however, that for the analysis from birth to first calving, all animals were in the same feed group. $\beta_{m}$ are the fixed regression coefficients, $\gamma_{\text {im }}$ are the random regression coefficients associated with the animal plus its permanent environment, and $\varepsilon_{i t}$ is the residual error associated with days since birth $t . \mathrm{X}_{\mathrm{m}}(\mathrm{t})$ is the mth ordinary polynomial evaluated at $t, \mathrm{P}_{\mathrm{m}}(\mathrm{t})$ is the $\mathrm{mth}$ Legendre polynomial evaluated at time $t$, and the parameters $f$ and $k$ are the order of the fixed and random polynomials, respectively. The overall trend curve was modeled using an ordinary polynomial because they are easier to differentiate to provide growth rates.

Two datasets were analyzed separately. The first dataset consisted of all records from birth through first calving; the second dataset contained BW measurements up to $1,825 \mathrm{~d}$ of life. Observations in the first dataset beyond $\mathrm{d} 730$ and in the second dataset beyond d 1,825 were deleted, as they were few in number and were potential outliers. This yielded 4,912 records in the first dataset and 47,278 in the second dataset. We analyzed these data separately as we judged that a more precise picture of precalving growth would be obtained from modeling data from birth to first calving than from modeling data from birth to around $5 \mathrm{yr}$ of age. For growth from birth to first calving, the overall trend was modeled using a cubic regression of $\mathrm{BW}$ on days of life. Deviations of individual animals from this general curve were modeled using random regressions of order 4. A higher order fixed curve did not improve the fit of the model to the data, and an attempt to increase the order of the random polynomials resulted in a failure to converge. For the complete dataset, fixed regressions of BW on time were fitted as ordinary polynomials of degree 6 , and animal deviations from this overall curve were modeled using Legendre polynomials up to order 5. Again, attempts to increase the order of fixed and random polynomials either failed to im- prove the fit of the model to the data or resulted in nonconvergence. The first differentials of the fixed polynomials describing the overall curves were calculated to produce average curves of daily rate of gain.

Residual, or measurement, errors were expected to have heterogeneous variances associated with management events, such as weaning and turn-out. Therefore, different residual errors were associated with observations over time. The first 2 classes were defined as BTW $(\mathrm{d}$ of life $=0$ ) and WW. Thereafter, classes were defined as days of life of varying sizes to approximate to stages of lactation (Table 1). These classes were defined to provide sufficient records in each class and also to be coincident to stages of lactation that affect residual error variance (Coffey et al., 2002). Within classes, residual errors were assumed to be homogeneous, and between classes, residual covariances were assumed to be zero.

\section{Genetic Analysis}

Data were extracted on 486 cows with BTW, WW, and CW present. There were 1,296 animals in the associated pedigree file. Genetic line and year-week of measurement were fitted in the model as fixed effects, and day of life was included for WW and CW as a linear and quadratic covariate. Cow was included as a random genetic effect. All traits were analyzed simultaneously to estimate phenotypic and genetic correlations between the traits.

If BTW, WW, and CW were genetically the same trait, the true genetic correlation among them would be 1.0. To obtain a range within which we are confident that each of our correlations lies, confidence intervals were estimated (Spiegel, 1961). Because the sampling distribution of a correlation coefficient is not normal, we converted each of the genetic correlations to Fisher's Z statistic. The sampling distribution of this statistic is approximately normal with standard error $1 / \sqrt{N-3)}$,

allowing us to set up a confidence interval for each statistic. A back transformation yielded confidence intervals for each of the genetic correlations.

\section{RESULTS}

\section{Phenotypic Analyses}

Summary statistics for select and control line cows for all days of life up to d 1,825 are given in Figures 1 and 2 and in Table 1. Figure 1 shows that the average first-lactation yield of select heifers rose from 6,500 to $8,800 \mathrm{~kg}$ during the period, whereas the average yield of control heifers rose from 5,600 to $7,300 \mathrm{~kg}$. For both groups, there was no clear pattern of BW at first calving 
Table 1. Number of records in each of the 26 residual error classes and the corresponding phenotypic mean $(\mathrm{kg})$, standard deviation, and residual error variances (REV) for nonpregnant live weight for all cows

\begin{tabular}{|c|c|c|c|c|c|}
\hline \multirow[b]{2}{*}{ Days of life } & \multicolumn{5}{|c|}{ Nonpregnant live weight } \\
\hline & Records & Mean & SD & $\begin{array}{l}\text { REV } \\
\text { (d 0-730) }\end{array}$ & $\begin{array}{l}\text { REV } \\
\text { (d 0-1,825) }\end{array}$ \\
\hline & (no.) & $(\mathrm{kg})$ & & $\longrightarrow$ & \\
\hline Birth & 622 & 43.4 & 4.93 & 2.92 & 40.5 \\
\hline Weaning (36-69) & 625 & 69.8 & 8.38 & 19.54 & 86.6 \\
\hline $100-199$ & 300 & 188.8 & 24.45 & 106.2 & 544.6 \\
\hline $200-299$ & 672 & 240.4 & 31.75 & 96.4 & 379.1 \\
\hline $300-399$ & 490 & 329.0 & 37.74 & 170.1 & 417.4 \\
\hline $400-499$ & 588 & 398.3 & 40.66 & 198.5 & 536.7 \\
\hline $500-729$ & 2,023 & 496.2 & 49.17 & 301.8 & 900.8 \\
\hline $730-739$ & 442 & 519.1 & 43.48 & & 612.6 \\
\hline $740-749$ & 531 & 520.9 & 45.10 & & 579.9 \\
\hline $750-759$ & 563 & 522.7 & 43.39 & & 403.5 \\
\hline $760-789$ & 1,872 & 528.5 & 44.31 & & 316.2 \\
\hline $790-889$ & 6,497 & 545.8 & 48.87 & & 157.0 \\
\hline $890-1,094$ & 9,602 & 556.0 & 52.95 & & 352.9 \\
\hline $1,095-1,104$ & 335 & 585.4 & 48.25 & & 622.0 \\
\hline $1,105-1,114$ & 351 & 584.3 & 46.94 & & 454.1 \\
\hline $1,115-1,124$ & 365 & 584.5 & 46.69 & & 496.4 \\
\hline $1,125-1,154$ & 1,205 & 590.7 & 47.91 & & 454.0 \\
\hline $1,155-1,254$ & 4,416 & 603.8 & 52.39 & & 278.1 \\
\hline $1,255-1,459$ & 6,849 & 606.2 & 57.94 & & 403.2 \\
\hline $1,460-1,469$ & 217 & 628.9 & 50.10 & & 628.1 \\
\hline $1,470-1,479$ & 231 & 625.4 & 50.93 & & 533.9 \\
\hline $1,480-1,489$ & 271 & 628.7 & 48.51 & & 625.9 \\
\hline $1,490-1,499$ & 257 & 630.4 & 49.84 & & 542.9 \\
\hline $1,500-1,529$ & 857 & 630.2 & 49.23 & & 525.2 \\
\hline $1,530-1,629$ & 3,077 & 633.0 & 51.97 & & 291.8 \\
\hline $1,630-1,825$ & 4,020 & 633.4 & 56.52 & & 341.4 \\
\hline
\end{tabular}

over time, but select cows were approximately $30 \mathrm{~kg}$ heavier than control cows at first calving (Figure 2).

Residual error variance (Table 1) was low for BTW and for WW but remained high for the remainder of the growth trajectory. Residual error variance was highest at the point where days of life did not map exactly to lactation number. This is where cows at different stages of lactation were at similar days of life, and it occurred at the boundary of calving dates. Residual error variance was reduced during each lactation

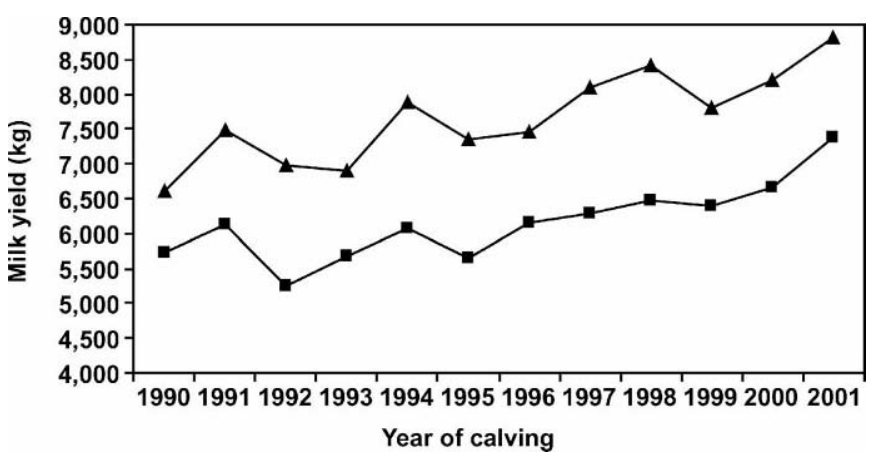

Figure 1. Average first-lactation milk yield (kg) by year of first calving for select $(\boldsymbol{\Delta})$ and control ( $\boldsymbol{\square})$ cows. but rose again as the next lactation approached. Residual error variance was lower in the analysis of data collected before first calving than from the full dataset. These data contain no BW records taken after calving and, therefore, are unperturbed by calving and lactation. As suspected, goodness of fit for pre-first calving observations was superior when only pre-first calving data were included.

In both analyses, year of birth removed a significant amount of variation in live weight, but no additional

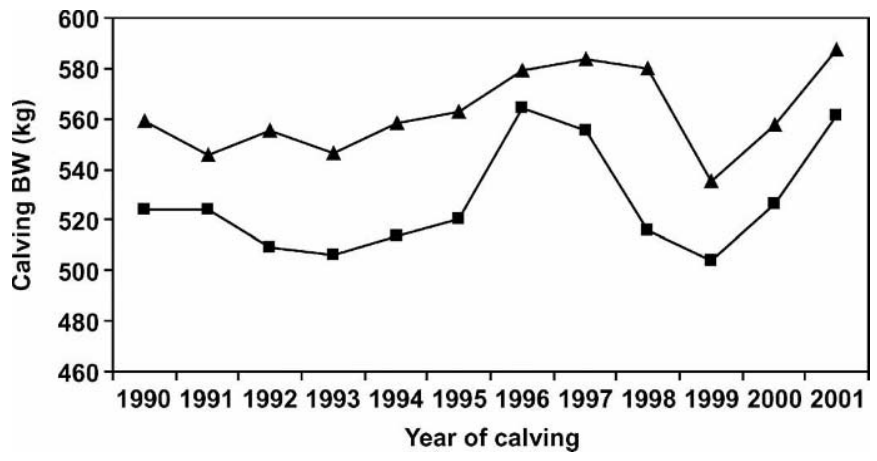

Figure 2. Average BW at first calving (kg) by year of first calving for select ( $\mathbf{\Delta})$ and control ( $\mathbf{\square})$ cows. 


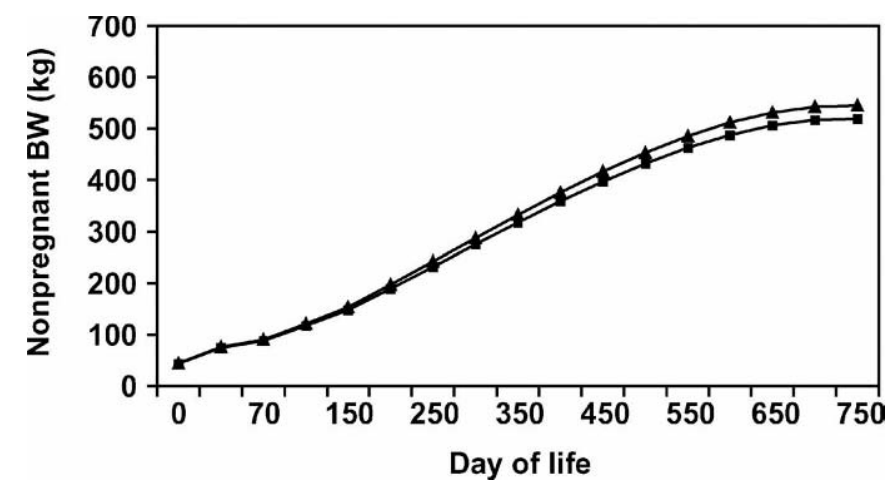

Figure 3. Pregnancy-adjusted live weight $(\mathrm{kg})$ for each day of life from birth to d 730 for select (A) and control (ם) cows.

variation was accounted for by the interaction of genetic line with year of birth. Feed group (where applicable) and its interaction with genetic line were both statistically significant.

Fitted BW curves from birth to d 730 are given in Figure 3. The standard errors of all fitted values were estimated from the standard errors of the regression coefficients and the covariances between them. No significant difference in BW between the lines at birth was found, but from around d 50 onward, the lines differed significantly in BW $(P<0.01 ; t$-test $)$. From this point until first calving, select line cows were significantly heavier than control line cows $(P<0.01)$; the difference between the lines reached $25 \mathrm{~kg}$ at first calving.

The corresponding average growth rate curve from birth to d 730 is given in Figure 4. Because the bestfitting overall curve was a cubic regression of BW on days of life, the growth rate curve is a quadratic function of time. From birth, select line cows grow at a significantly faster rate than control line cows $(P<0.01)$ until around d 625 when there is no significant difference in

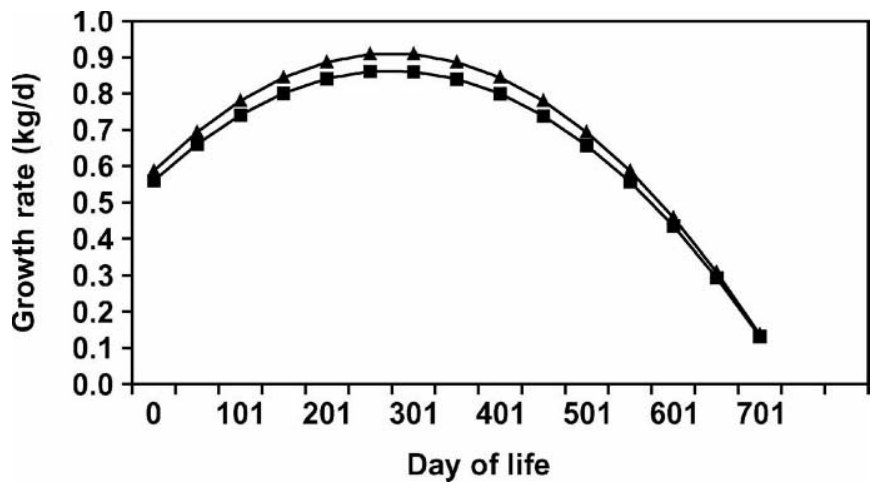

Figure 4. Growth rate for pregnancy-adjusted live weight (kg/d) for each day of life from birth to $d 730$ for select $(\mathbf{\Delta})$ and control (ם) cows.

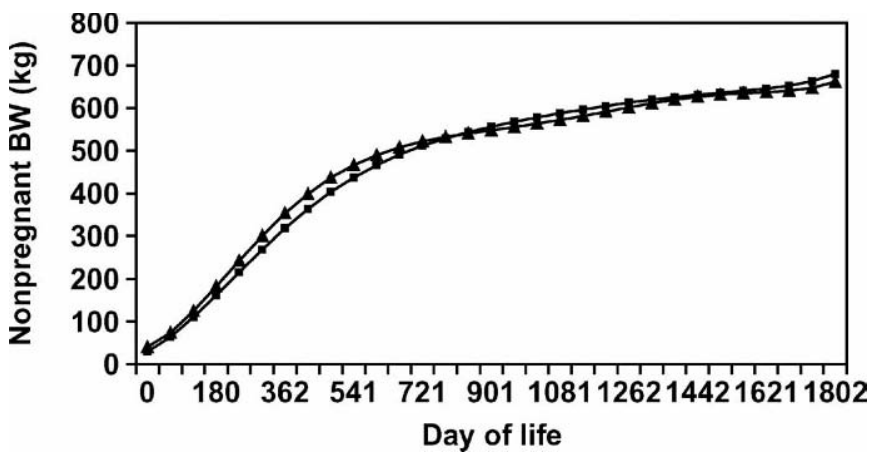

Figure 5. Pregnancy-adjusted live weight $(\mathrm{kg})$ for each day of life from birth to d 1,825 for select ( $\mathbf{\Delta})$ and control (ם) cows.

the growth rate between the lines. Figure 2 demonstrates that growth increases at a steady rate from birth to around d 280, peaks at around $0.90 \mathrm{~kg} / \mathrm{d}$ for select cows and $0.86 \mathrm{~kg} / \mathrm{d}$ for control cows, and then declines toward first calving.

Fitted BW curves for nonpregnant live weight from birth to d 1,825 are given in Figure 5. Select cows are heavier before and at first calving $(P<0.01)$. Control cows are significantly $(P<0.01)$ heavier than select cows between 30 and 40 mo of age, but by the end of third lactation, there is no significant difference in BW between the lines. This may imply that select cows reach maturity earlier or that they are willing to sustain a reduction in growth after calving to a greater extent than control cows. This reduced rate of growth will include a reduction in body lipid because condition score loss is pronounced in select animals in this herd (Coffey et al., 2002).

The average growth rate curves for these cows are given in Figure 6. As the BW curves were polynomials of degree 6 , these curves are polynomials of degree 5 .

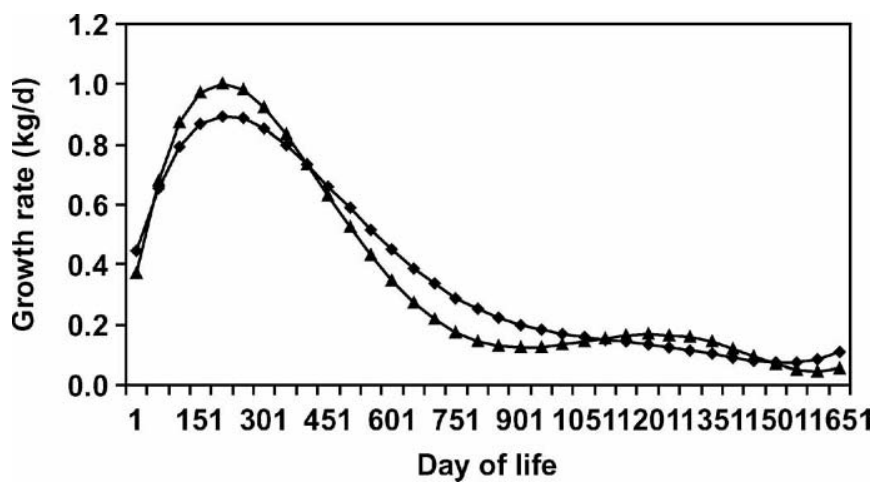

Figure 6. Growth rate for pregnancy-adjusted live weight $(\mathrm{kg} / \mathrm{d})$ for each day of life from birth to d 1,825 for select ( $\mathbf{A})$ and control (ם) cows. 
Table 2. Correlations between live weight on a selection of days. The day of life for weaning in this table is 42 .

\begin{tabular}{lllllll}
\hline Day & Weaning & 199 & 399 & 730 & 1,100 & 1,500 \\
\hline Birth & 0.50 & -0.08 & 0.03 & 0.25 & 0.18 & 0.02 \\
Weaning & & 0.77 & 0.55 & 0.25 & 0.35 & 0.28 \\
199 & & 0.83 & 0.38 & 0.35 & 0.38 \\
399 & & & 0.78 & 0.50 & 0.42 \\
730 & & & & & 0.76 \\
1,000 & & & & & 0.67 \\
1,400 & & & & & & \\
\hline
\end{tabular}

Both lines have positive growth rates throughout the entire trajectory. Select cows grow at a faster rate from soon after birth until around d 450, at which time the growth rate of the control cows exceeds that of the select cows. During first lactation and second lactation, control cows grow at a significantly faster rate than select cows $(P<0.01)$, but from just before third calving (around $d 1,400$ ) onward, there is no significant difference in growth rate between the lines.

Table 2 gives correlations between animal solutions for BW on a selection of days of life, including first calving (approximately d 730), second calving (around $\mathrm{d} 1,100$ ), and third calving (approximately d 1,500). The correlation between BTW and WW (assumed d 42) is moderate (0.50) but low between BTW and BW at all other days of life. Between all other BW, correlations were moderate to high, ranging from 0.25 to 0.83 .

\section{Genetic Analysis}

No significant difference between the lines was found for BTW and WW, whereas lines differed significantly for $\mathrm{CW}$. The quadratic coefficients of days of life, fitted in the models for WW and CW, were not significantly different from zero. For both traits, linear coefficients differed significantly from zero. Interpreting these linear coefficients as growth rates suggests a growth rate at weaning of $0.60 \mathrm{~kg} / \mathrm{d}$ and at first calving of $0.53 \mathrm{~kg} / \mathrm{d}$.

Heritabilities, genetic correlations, and phenotypic correlations are given in Table 3, together with standard errors. Heritabilities were moderate to high for all BW traits, ranging from 0.45 (WW) to $0.75(\mathrm{CW})$. Genetic correlations were intermediate to high among

Table 3. Genetic correlations (above diagonal), phenotypic correlations (below diagonal), and heritabilities for birth weight (BTW), weaning weight (WW), and calving weight $(\mathrm{CW})$. Standard errors are presented in parentheses.

\begin{tabular}{llll}
\hline & BW & WW & CW \\
\hline BW & $0.53(0.12)$ & $0.79(0.09)$ & $0.50(0.16)$ \\
WW & $0.73(0.03)$ & $0.45(0.12)$ & $0.59(0.15)$ \\
CW & $0.30(0.07)$ & $0.43(0.06)$ & $0.75(0.11)$ \\
\hline
\end{tabular}

all body traits and decreased with increasing time between BW measurements. Phenotypic correlations were slightly lower than genetic correlations and also decreased with increasing time interval.

A 99\% confidence interval for each of the genetic correlations gave a confidence interval for the correlation between BTW and WW of 0.75 to 0.83 . Similarly, the confidence interval for the genetic correlation between BTW and CW was 0.42 to 0.57 ; between WW and CW, the confidence interval was 0.52 to 0.65 . Therefore, we have no evidence that these traits are under the same genetic control. Note also that correlations given in $\mathrm{Ta}$ ble 2 suggest that at least BTW is a different trait in comparison with other BW traits.

\section{DISCUSSION}

Live weight from birth to first calving was analyzed twice: 1) using data from birth to first calving and a cubic polynomial and 2) using data from birth to the end of third lactation and a polynomial of degree 6 . Both analyses showed that select cows were significantly heavier than control cows from just after birth to first calving. The first analysis found that the growth rate of select cows exceeded that of control cows from birth to $\mathrm{d} 625$, whereas the second analysis concluded that the growth rate of select cows was significantly higher from birth to $\mathrm{d} 450$. This difference is a function of the different data and models used, and by restricting the analysis to a portion of the total trajectory, we have managed to utilize a lower order (less "wavy") polynomial. Therefore, we suggest that the results from the first analysis are more accurate.

The onset of puberty is determined by BW as heifers start to cycle at approximately $43 \%$ of mature BW (Van Amburgh and Dalton, 1993). Although reducing age at first calving and, hence, reducing the nonproductive period of heifers lowers input costs (Mourits et al., 1997), a study by Hansen et al. (1999) found that cows in a small (body size) line required fewer services to conception during first lactation than did cows in a large (body size) line. They also found that productive life to a maximum of $6 \mathrm{yr}$ was $15.4 \%$ longer for cows in the 
small line than for those in the large line. Results presented here demonstrate that selection for milk production in first-lactation Holsteins has led to dairy cattle with significantly different growth curves prior to first calving and significantly different BW at first calving. There was no significant difference in BW by the end of third lactation, but $41 \%$ of the control cows completed 3 lactations, whereas only $34 \%$ of cows in the select line did so. This might have implications for the management of animals selected for production in order to optimize lifetime performance. Similarly, growth prior to first lactation could be included in future selection policies to optimize the expression of lifetime utility (including fitness) of dairy cattle in modern management systems.

The animals used in this study were all managed together prior to first calving; therefore, differences in growth are expected to be a reflection of their genetic merit for growth. However, once lactation starts, growth is perturbed by lactation and the energetic demands associated with it. The effect of lactation on growth will be, in part, dependent on the degree of maturity of the animal at that point. It would be expected to be greater on the control cows, as they are growing at a faster rate postcalving. If growth has a higher priority than lactation in control cows, lactation would suffer at the expense of some degree of compensatory growth. This was not estimated in this study but could be investigated in a future study by looking at growth curves and the persistency of lactation to see whether control cows penalize persistency in order to grow.

Events occurring at one part of an animal's life may impart a legacy on subsequent performance such that subsequent management intervention is ultimately fruitless or at least less efficient. Dairy heifers that have a managed growth rate during critical points of mammary development and gestation accumulate proportionately less lipid than protein in mammary tissue. Their subsequent lactation is thereby enhanced (Choi et al., 1997). However, growth rate, onset of puberty, and pelvic dimensions were not related to serum immunoglobulin concentrations in the first few weeks of life (Ramin et al., 1996), implying no relationship between growth and susceptibility to disease.

In a study to examine the effects of plane of nutrition on age and body composition at puberty, Chelikani et al. (2003) found that diet affected the relative proportions of lipid and protein in growing Holstein heifers. Age at puberty was significantly lower in heifers fed a high protein diet. Coffey et al. (2002) analyzed live weight changes over 3 lactations in dairy cattle selected for fat plus protein yield or selected to remain at average fat plus protein and fed on a high-concentrate diet or a low-concentrate diet. Those researchers showed that select line cows were significantly heavier at first calving, but by the end of 3 lactations, there was no significant difference in BW between the 2 lines regardless of the diet they had been fed.

Lee et al. (1992), in an analysis of 1,266 Holstein cows born between 1972 and 1983, estimated the heritability of BW at first calving as 0.33 , and the heritability of BW gain from 0 to $8 \mathrm{wk}$ of age as 0.24 . Groen and Vos (1995) analyzed BW data taken at various time points from birth to first calving on 631 Dutch Black and White animals born from 1983 to 1990 using an animal model. They estimated the heritability of BTW as 0.46 and the heritability of $\mathrm{CW}$ as 0.64 . Our data consisted of animals born from 1990 to 2002, and our estimates of heritability are consistent with those of Groen and Vos (1995), but higher than those of Lee et al. (1992). Higher heritabilities obtained from both this analysis and the analysis of Groen and Vos (1995) may well be a result of the uniform recording conditions under which both sets of data were collected.

The magnitude of the genetic correlation between BTW and CW suggests that these traits may be under the control of different genes. In a QTL analysis of BW at specific times in chickens, Carlborg et al. (2003) drew similar conclusions. Most QTL affected either early or late growth, and few loci affected the whole growth process. Cheverud et al. (1996) and Vaughan et al. (1999) showed that QTL affecting early and late growth were generally distinct, mapping to different chromosomal locations in mice, indicating separate genetic and physiological systems for early and late growth.

\section{CONCLUSION}

Growth in Holstein dairy heifers has been significantly altered in line with selection, primarily for yield. This alteration might have consequences in later productive life for economically important traits such as health, fertility, and survival.

\section{ACKNOWLEDGMENTS}

We thank the Scottish Executive Environment and Rural Affairs Department for funding the Langhill Dairy Research Centre, which provided data for this study. We also thank Ian White for helping us "tweak" the software to provide differences in growth rate and the appropriate standard errors.

\section{REFERENCES}

Arango, J. A. and L. D. Van Vleck. 2002. Size of beef cows: Early ideas, new developments. Genet. Mol. Res. 31:51-63. 
ARC. 1980. The Nutrient Requirement of Ruminant Livestock. Technical Review by an Agricultural Research Council Working Party. $\mathrm{CAB}$ International, Wallingford, UK.

Carlborg, O., S. Kerje, K. Schutz, L. Jacobsson, P. Jensen, and L. Andersson. 2003. A global search reveals epistatic interaction between QTL for early growth in chickens. Genome Res. 13:413-421.

Chelikani, P. K., J. D. Ambrose, and J. J Kenelly. 2003. Effect of dietary energy and protein density on body composition, attainment of puberty, and ovarian follicular dynamics in dairy heifers. Theriogenology 60:707-725.

Cheverud, J. M., E. J. Routman, F. A. Duarte, B. van Swinderen, K. Cothran, and C. Perel. 1996. Quantitative trait loci for murine growth. Genetics 142:1305-1319.

Choi, Y. J., I. K. Han, J. H. Woo, K. Jang, K. H. Myung, and Y. S. Kim. 1997. Compensatory growth in dairy heifers: The effect of a compensatory growth pattern on growth rate and lactation performance. J. Dairy Sci. 80:519-524.

Coffey, M. P., G. Simm, and S. Brotherstone. 2002. Energy balance for the first three lactations of dairy cows estimated using random regression. J. Dairy Sci. 85:2669-2678.

Coffey, M. P., G. Simm, W. G. Hill, and S. Brotherstone. 2003. Genetic evaluations of dairy bulls for daughter energy balance profiles using linear type scores and body condition score analyzed using random regression. J. Dairy Sci. 86:2205-2212.

Demeke, S., F. W. C. Neser, and S. J. Schoeman. 2003. Variance components and genetic parameters for early growth traits in a mixed population of purebred Bos indicus and crossbred cattle. Livest. Prod. Sci. 84:11-21.

Enevoldsen, C., and T. Kristensen. 1997. Estimation of body weight from body size measurements and body condition scores in dairy cows. J. Dairy Sci. 80:1988-1995.

Gilmour, A. R., B. R. Cullis, S. J. Welham, and R. Thompson. 1998. ASREML User's Manual, October, 1998. New South Wales Agriculture, Orange Agricultural Institute, Orange, NSW, Australia.

Groen, A. F., and H. Vos. 1995. Genetic parameters for body weight and growth in Dutch Black and White replacement stock. Livest. Prod. Sci. 41:201-206.

Hansen, L. B., J. B. Cole, G. D. Marx, and A. J. Seykora. 1999. Productive life and reasons for disposal of Holstein cows selected for large versus small body size. J. Dairy Sci. 82:795-801.

Hoffman, P. C., and D. A. Funk. 1992. Applied dynamics of dairy replacement growth and management. J. Dairy Sci. 76:31793187.

Kirkpatrick, M., D. Lofsvold, and M. Blmer. 1990. Analysis of inheritance, selection and evolution of growth trajectories. Genetics 124:979-993.

Koenen, E. P. C., and A. F. Groen. 1998. Genetic evaluation of body weight of lactating Holstein heifers using body measurements and conformation traits. J. Dairy Sci. 81:1709-1713.
Koenen, E. P. C., A. F. Groen, and N. Gengler. 1999. Phenotypic variation in live weight and live-weight changes of lactating Holstein-Friesian cows. Anim. Sci. 68:109-114.

Korver, S., E. A. M. Van Eekelen, H. Vos, G. J. Nieuwhof, and J. A. M. Van Arendonk. 1991. Genetic parameters for feed intake and feed efficiency in growing dairy heifers. Livest. Prod. Sci. $29: 49-59$.

Lee, A. J., D. A. Boichard, A. J. McAllister, C. Y. Lin, K. Nadarajah, T. R. Batra, G. L. Roy, and J. A. Vesely. 1992. Genetics of growth, feed intake, and milk yield in Holstein cattle. J. Dairy Sci. 75:3145-3154.

Mantysaari, P., M. Ojala, and E. Mantysaari. 2002. Measures of before and after breeding daily gains of dairy replacement heifers and their relationship with first lactation milk production traits. Livest. Prod. Sci. 75:313-322.

Mourits, M. C. M., A. A. Dijkhuizen, R. B. M. Huirne, and D. T. Galligan. 1997. Technical and economic models to support heifer management decisions: Basic concepts. J. Dairy Sci. 80:14061415.

Pryce, J. E., B. L. Nielsen, R. F. Veerkamp, and G. Simm. 1999. Genotype and feeding system effects and interactions for health and fertility traits in dairy cattle. Livest. Prod. Sci. 57:193-201.

Ramin, A. G., R. C. W. Daniel, D. C. Fenwick, and R. G. Verrall. 1996. Serum immunoglobulin concentrations in young dairy calves and their relationships with weight gain, onset of puberty and pelvic area at 15 months of age. Livest. Prod. Sci. 45:155-162.

Spelman, R. J., and D. J. Garrick. 1997. Effect of live weight and differing economic values on responses to selection for milk fat, protein, volume, and live weight. J. Dairy Sci. 80:2557-2562.

Spiegel, M. R. 1961. Statistics. McGraw-Hill Book Co., New York, NY.

Stelwagen, K., and D. G. Grieve. 1990. Effect of plane of nutrition on growth and mammary gland development in Holstein heifers. J. Dairy Sci. 72:2333-2341.

Van Amburgh, M. E., and D. M. Dalton. 1993. Growth and nutrition of heifers from weaning to breeding weight. No. 165 in Proc. Second Biennial Northeast Heifer Manage. Symp., Cornell Univ., Ithaca, NY.

Van Amburgh, M. E., D. G. Fox, D. M. Galton, D. E. Bauman, and L. E. Chase. 1998. Evaluation of National Research Council and Cornell Net Carbohydrate and Protein Systems for predicting requirements of Holstein heifers. J. Dairy Sci. 81:509-526.

Vaughan, T. T., L. S. Pletscher, A. Peripato, K. King-Ellison, E. Adams, C. Erikson, and J. M. Cheverud. 1999. Mapping quantitative trait loci for murine growth: A closer look at genetic architecture. Genet. Res. 74:313-322.

Veerkamp, R. F., G. Simm, and J. D. Oldham. 1995. Genotype by environment interaction-Experience from Langhill. Pages 5966 in Breeding and Feeding the High Genetic Merit Dairy Cow. British Society of Animal Science Occasional Publication. No. 19 T. L. J. Lawrence, F. J. Gordon, and A. Carson, ed. Br. Soc. Anim. Sci., Edinburgh, UK

Wolf, C. A. 2003. Custom dairy heifer grower industry characteristics and contract terms. J. Dairy Sci. 86:3016-3022. 